
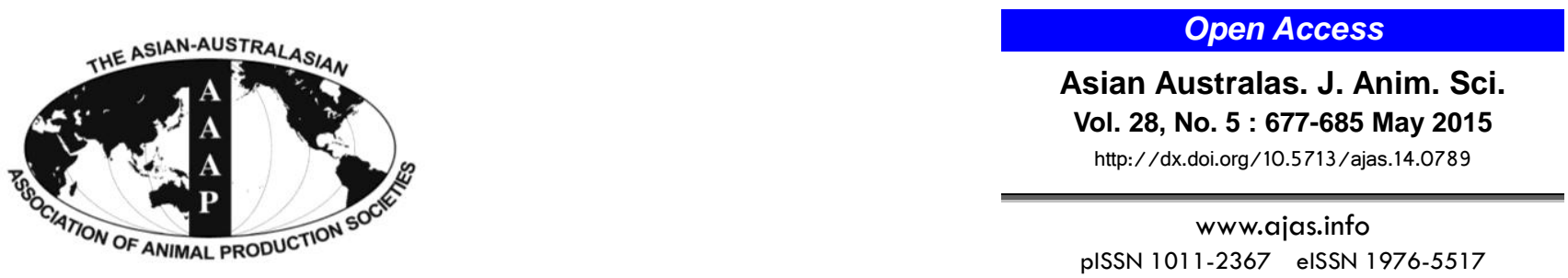

\title{
The Impact of Ripening Time on Technological Quality Traits, Chemical Change and Sensory Characteristics of Dry-cured Loin
}

\author{
Pil Nam Seong, Kyoung Mi Park, Geun Ho Kang, Soo Hyun Cho, Beom Young Park, and Hoa Van Ba* \\ Animal Products and Processing Division, National Institute of Animal Science, Suwon 441-706, Korea
}

\begin{abstract}
The effect of ripening time on the technological quality traits, fatty acid compositions and sensory characteristics of drycured loin was studied. Pork loins $(n=102)$ at $24 \mathrm{~h}$ post-mortem were used to produce dry-cured loins. The dry-cured loins were assessed at 30,60, and 90 days of ripening for the aforementioned characteristics. Our results showed that the water activity $\left(\mathrm{a}_{\mathrm{w}}\right)$ decreased $(\mathrm{p}<0.05)$ up to 60 days and did not change thereafter. The lipid oxidation and weight loss levels significantly $(\mathrm{p}<0.05)$ increased with increased ripening time. The Commission Internationale de l'Eclairage (CIE) L* decreased for 90 days while CIE a* increased for 60 days and did not increase thereafter. More noticeably, the levels of most of unsaturated fatty acids and total polyunsaturated fatty acids significantly decreased as increasing ripening time up to 90 days. The 30 days-ripened loins had lower $(\mathrm{p}<0.05)$ color, flavor and overall acceptability scores than the loins ripened for 60 and 90 days, however, no differences in sensory traits occurred between the 60 and 90 day-ripened samples. Based on the results obtained in the present study, it is suggested that the ripening duration between 30 and 60 days could be more appropriate for producing dry-cured loin product with higher quality and economic benefits. (Key Words: Dry-cured Ham, Ripening Time, Quality, Fatty Acid, Sensory)
\end{abstract}

\section{INTRODUCTION}

The demand for livestock products has rapidly increased in recent times compared to that before the $1989 \mathrm{~s}$ as a result of the income and population growths, as well as along with changing food preferences (FAO, 2013). However, consumers' demands meat products with high quality, safety, health benefit, palatability and convenience. Therefore, modification of processing technology aiming to improve quality and palatability of meat products is needed to meet the consumer's demands. Otherwise, research and development of new products are also important tasks of researchers and producers, which help not only consumers to have more opportunities to choose and savor new products but also to promote the processing and production of meat materials.

The loin is considered as one of the most economically important parts in a pig carcass. For this reason, it has

\footnotetext{
* Corresponding Author: Hoa Van Ba. Tel: +82-31-290-1699, Fax: +82-31-290-1697, E-mail: hoavanba@jbnu.ac.kr Submitted Oct. 10, 2014; Revised Dec. 2, 2014; Accepted Dec. 16, 2014
}

become the most frequently used muscle in studies regarding the meat quality characteristics (Jonsall et al., 2002; Meinert et al., 2009). In general, the muscle is usually used to process into variety of dishes depending on culture and preference of each region in each country for instance, the muscle is apparently thoroughly cooked in various dishes in all countries (Vittadini et al., 2005; Chiavaro et al., 2009). However, processing of this muscle into final products for instance, ready-to-eat products with high nutritional value, typical palpability and convenience to use is necessary to add value to this muscle far beyond its usual profitability. So far, dry-cured loin is one of the most popular meat products processed from pork longissimus dorsi muscle, and has been received considerable attention by consumers due its palatability and typical flavor (Hernandez et al., 1999; Muriel et al., 2004; Ventanas et al., 2005). Practically, the dry-cured loin is produced by rubbing a mixture of curing agents (salt and nitrite) and other additives onto the surface of the loin, then stuffed into casings and eventually subjected to the drying/ripening processes (Flores and Toldra, 1993). During the ripening process, the product becomes partially dried and develops

Copyright $@ 2015$ by Asian-Australasian Journal of Animal Sciences This is an open-access article distributed under the terms of the Creative Commons Attribution Non-Commercial License (http://creativecommons.org/licenses/by-nc/3.0/), which permits unrestricted non-commercial use, distribution, and reproduction in any medium, provided the original work is properly cited. 
its typical aroma and taste characteristics due to the biochemical changes (Hernandez et al., 1999). However, it has been reported that the quality characteristics of drycured meat products as a whole are greatly affected by a number of factors related to the raw material and processing technology (Andres et al., 2004; Jurado et al., 2007). Regarding the raw material effect, previous studies have reported that the rearing system and breeding are among the underlying factors directly affecting the raw pork meat quality which subsequently impacts the quality of dry-cured loin (Muriel et al., 2004; Ventanas et al., 2006; Soto et al., 2008). On the other hand, similar to the other types of cured meat products, the quality of dry-cured loin is probably also influenced by the processing technology (e.g., length of drying/ripening period), however, this still remains unknown because no study has been conducted to elucidate this issue. Practically, the product, after draining and casing, is subjected to ripening/drying for several months until the water activity $\left(\mathrm{w}_{a}\right)$ reduces below 0.90 (Soto et al., 2008), thus, extent of the ripening/drying time may cause an increase in weight loss which probably affects the quality characteristics and nutritional value as well as production cost of dry-cured loin (e.g., time and electric expenses). Therefore, determination of the ripening period at which the product possesses the highest quality and economic efficiency is very important for processors and meat processing industry.

Though the product has been developed, distributed, consumed and become popular in several markets such as Spain (Hernandez et al., 1999) as well as its quality characteristics has also been characterized by some researchers (Hernandez et al., 1999; Ventanas et al., 2006), it is apparently quite unfamiliar with many markets especially to the Asia consumers. Furthermore, most of previous studies have only focused on the raw material effect, whereas it still remains unknown whether the processing technology affects the quality characteristics and economic benefit of dry-cured loin. Therefore, to promote the processing, consumption and commercialization of this product at globalization scale, more detailed studies regarding the processing factors affecting the quality characteristics, shelf-life stabilities and palatability of this product are needed. Thus, the main aim of this work was to elucidate how the technological quality traits, color, fatty acids and sensory characteristics of dry-cured loins processed from Korean native pigs are affected by ripening periods (30, 60, and 90 days). The findings of the present study could be useful for meat processors to produce drycured loin product with high quality and economic benefit.

\section{MATERIAL AND METHODS}

\section{Manufacture of dry-cured loin}

One hundred-two loins (longissimus thoracis et lumborum [LTL]) of Korean native pigs with an average weight of $1.7 \pm 0.2 \mathrm{~kg}$ and a mean $\mathrm{pH}$ value measured at $24 \mathrm{~h}$ post-mortem of $5.66 \pm 0.02$ selected from a commercial slaughterhouse (Jeju, Korea), were used to process into drycured loins. Manufacture of dry-cured loins was performed in a pilot plant of National Institute of Animal Science in Korea. All dry-cured loins were processed the same day using the same ingredients and formulation. The levels of curing agents such as salt and nitrite, and the ripening conditions (e.g., temperature and relative humidity) used for processing of dry-cured loins in the present work were referred to previous studies (Ventanas et al., 2007; Alino et al., 2010) with minor modifications. Before processing, the pork loins were trimmed of all surface fat and connective tissue, and were then salted by rubbing a mixture containing $2.5 \%(\mathrm{w} / \mathrm{w}) \mathrm{NaCl}, 2.0 \%(\mathrm{w} / \mathrm{w})$ sugar, $0.2 \%(\mathrm{w} / \mathrm{w})$ ascorbic acid, $0.01 \%(\mathrm{w} / \mathrm{w}) \mathrm{NaNO}_{2}, 0.1 \%(\mathrm{w} / \mathrm{w})$ citric acid and $0.1 \%$ (w/w) black pepper on the surfaces. The salted loins were kept for 7 days at $4^{\circ} \mathrm{C}$ to allow the seasoning mixture to penetrate (post-salting without casing). Afterwards, each loin was stuffed into natural bovine casings, tightened and held for 14 days at $4{ }^{\circ} \mathrm{C}$ with relative humidity of $85 \%$ (postsalting with casing). Eventually, they were hung up and ripened at $10^{\circ} \mathrm{C}$ and $75 \%$ relative humidity. The conditions employed throughout the processing periods are summarized in Table 1. The samples were collected at three different ripening periods, 30, 60, and 90 days (34 loins were used in each ripening period) and then used for analysis. The external cases of the dry-cured loins were discarded and then the loins were reweighted to determine the weight loss. Afterward, the dry-cured loins were cut into sub-sample sizes starting from cranial end of the LTL muscle depending on type of analysis (Figure 1). The subsamples were vacuum-packed in polyethylene bags and stored at $-20^{\circ} \mathrm{C}$ until analysis.

\section{Chemical composition analysis}

Moisture, protein, fat and ash contents were determined

Table 1. Conditions used throughout the processing of dry-cured loins

\begin{tabular}{|c|c|c|c|c|}
\hline Stage & & Temperature $\left({ }^{\circ} \mathrm{C}\right)$ & Relative humidity (\%) & Time $(\mathrm{d})$ \\
\hline Salting & & 4 & 90 & 1 \\
\hline \multirow[t]{2}{*}{ Post-salting } & Without casing & 4 & 90 & 7 \\
\hline & With casing & 4 & 85 & 14 \\
\hline Ripening & & 10 & 75 & $30,60,90$ \\
\hline
\end{tabular}




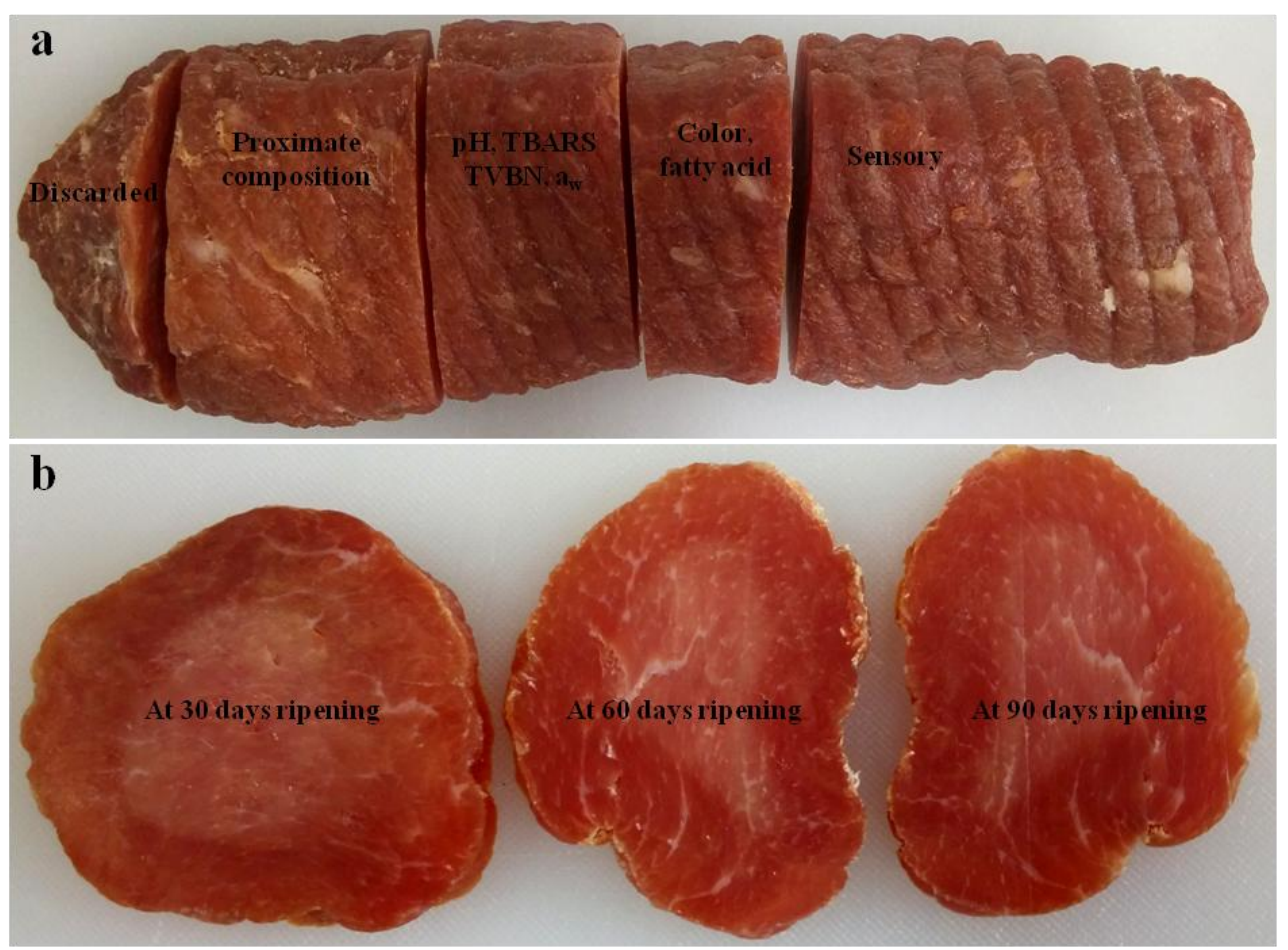

Figure 1. The representative images show (a) the preparation of sub-sample sizes of dry-cured loin for the analyses, and (b) the crosssection of dry-cured loins at 30,60, and 90 days ripening.

according to the procedures recommended by the AOAC international method (2000).

Water activity $\left(a_{w}\right)$ of the dry-cured loins was determined at $25^{\circ} \mathrm{C}$ with a Novasina measuring instrument (model AW SPRINT-TH 300, Pfaffikon, Switzerland). Calibration was done by using several saturated solutions of known $\mathrm{a}_{\mathrm{w}}$.

The $\mathrm{pH}$ value of dry-cured loin at different ripening periods was determined in triplicates using a $\mathrm{pH}$ meter (Model 340, Mettler-Toledo GmbH, Schwerzenbach, Switzerland). The $\mathrm{pH}$ was measured after homogenizing $3 \mathrm{~g}$ of each sample with $27 \mathrm{~mL}$ of distilled water for $30 \mathrm{~s}$ using a homogenizer (Polytron MR-2100, Kinematica AG, Lucerne, Switzerland).

\section{Color measurement}

Color parameters of the dry-cured loins were measured using a Minolta Chroma Meter CR-400 (Minolta Camera Co., Ltd., Osaka, Japan) that was standardized with a white plate $(\mathrm{Y}=86.3, \mathrm{X}=0.3165$, and $\mathrm{y}=0.3242)$. Color was expressed according to the Commission International de l'Eclairage (CIE) system and reported as CIE L* (lightness), CIE a* (redness), CIE b* (yellowness), chroma and hue angle $\left(\mathrm{h}^{\circ}\right)$. In which the chroma and hue angle were calculated as $\left(a^{* 2}+b^{* 2}\right)^{0.5}$ and $\tan ^{-1}(b * / a *)$, respectively. Each value was the mean of the readings taken at five different locations on the freshly cut surface of each sample after $30 \mathrm{~min}$ of blooming.

\section{Total volatile basic nitrogen determination}

The total volatile basic nitrogen (TVBN) content was determined following the method of Min et al. (2007) with suitable modifications. Briefly, sample (10 g each) was homogenized with $50 \mathrm{~mL}$ of distilled water and filtered through Whatman filter paper (No.1) (AEC scientific Co., Seoul, Korea). The filtrate $(1 \mathrm{~mL}$ each) was placed into the outer space of the Conway tool and $1 \mathrm{~mL}$ of $0.01 \mathrm{~N} \mathrm{H}_{3} \mathrm{BO}_{3}$ and $100 \mu \mathrm{L}$ of Conway reagent $(0.066 \%$ methyl red: $0.066 \%$ bromocresol green, $1: 1)$ were also added to the inner space. Then $1 \mathrm{~mL}$ of $50 \% \mathrm{~K}_{2} \mathrm{CO}_{3}$ was added to the outer space of Conway tool and was sealed immediately. The sealed Conway tool was incubated at $37^{\circ} \mathrm{C}$ for $120 \mathrm{~min}$ on a shaker. Finally, different volumes of $0.02 \mathrm{~N} \mathrm{H}_{2} \mathrm{SO}_{4}$ were added to the inner space to calculate the TVBN in the sample. The volatile basic nitrogen content was calculated by the following equation:

$$
\operatorname{TVBN} \%(\mathrm{mg} / 100 \mathrm{~g} \text { sample })=\frac{(\mathrm{X}-\mathrm{Y}) \times \mathrm{F} \times 28.014}{\mathrm{~S}} \times 100
$$

Where $\mathrm{S}$ is the meat sample weight in grams, $\mathrm{Y}$ is the volume of added $\mathrm{H}_{2} \mathrm{SO}_{4}$ in blank in $\mathrm{mL}, \mathrm{X}$ is the volume of added $\mathrm{H}_{2} \mathrm{SO}_{4}$ in the sample in $\mathrm{mL}$, and $\mathrm{F}$ is the standard factor of $\mathrm{H}_{2} \mathrm{SO}_{4}$.

\section{Lipid oxidation}

Lipid oxidation, evaluated by changes in thiobarbituric 
acid reactive substances (TBARS) as described by Pikul et al. (1987), was determined in dry-cured loin samples collected at different ripening periods. Briefly, each sample $(5 \mathrm{~g})$ with $17.5 \mathrm{~mL}$ of $4 \%$ perchloric acid and $0.5 \mathrm{~mL}$ of $7.5 \%$ butylated hydroxyansole in ethanol was homogenized at $13,000 \times$ rpm for $20 \mathrm{~s}$ using a homogenizer (Polytron MR2100, Kinematica AG, Switzerland). The volume of the homogenate was adjusted to $25 \mathrm{~mL}$ with $4 \%$ perchloric acid solution and then filtered through No. 1 Whatman filter paper. The filtrate $(5 \mathrm{~mL}$ each) was transferred to separate test tubes and mixed with $5 \mathrm{~mL}$ of $0.02 \mathrm{M}$ thiobarbituric acid solution, the mixture were then heated at $80^{\circ} \mathrm{C}$ for $1 \mathrm{~h}$ in a water-bath. After being cooled with cold water, about $1.5 \mathrm{~mL}$ of each sample was taken and the absorbance was measured at $532 \mathrm{~nm}$ using an UV-visible spectrophotometer (ProteomeLab Du-800, Beckman Coulter, Inc, Fullerton, CA, USA). The TBARS number was calculated by multiplying the absorbance by a constant coefficient of 5.5 which is obtained from standard curves and known dilutions $(0.1$ to $0.8 \mu \mathrm{M})$ of $1,1,3,3$ tetramethoxypropane (Aldrich, Saint Louis, MO, USA). The TBARS value was expressed as mg malonaldehyde/kg (MA/kg) of sample. Three repetitions were applied for each sample in each ripening period.

\section{Fatty acid composition}

Total lipids were extracted using chloroform-methanol $(2: 1 \mathrm{v} / \mathrm{v})$ according to the procedures Folch et al. (1957) and Morrison and Smith (1964) with suitable modification. Briefly, sample (20 g each) was homogenized with $150 \mathrm{~mL}$ of chloroform and methanol (2:1 v/v) mixture at 13,000x $\mathrm{rpm}$ for $30 \mathrm{~s}$. The homogenate was filtered through Whatman filter paper (No.1), and the filtrate was then centrifuged at $3,000 \times \mathrm{g}$ for $5 \mathrm{~min}$. Following the centrifuge, the supernatant was collected, placed in a $250 \mathrm{~mL}$ round bottom flask and then concentrated at $55^{\circ} \mathrm{C}$ for $10 \mathrm{~min}$ using an aspirator (Model S-3S, Korea Bio-Tech, Seoul, Korea). The concentrated samples (100 $\mu \mathrm{L}$ each) was placed into a $10 \mathrm{~mL}$ headspace vial with silicone-lined cap and then $1 \mathrm{~mL}$ of $0.5 \mathrm{~N} \mathrm{NaOH}$ in methanol was also added. The vial was capped and placed in a heating block maintained at $100^{\circ} \mathrm{C}$ for $20 \mathrm{~min}$ with vortex-mixed every 5 min. After being cooled at room temperature (RT) for 30 min, $2 \mathrm{~mL}$ of boron-trifluoride in methanol $(\mathrm{BDH}, \mathrm{BDH}$ Lab. Supplies, and Poole, England) was added, and the vial was again capped and placed in a heating block maintained at $100^{\circ} \mathrm{C}$ for $20 \mathrm{~min}$ with vortex-mixed every $5 \mathrm{~min}$. Following $30 \mathrm{~min}$ of cooling at RT, $8 \mathrm{~mL}$ of $100 \% \mathrm{NaCl}$ in heptane solution was added, vortexed for $1 \mathrm{~min}$ and then left for $1 \mathrm{~min}$ at RT. The upper phase $(1 \mathrm{~mL})$ was transferred to gas-liquid chromatography auto-sampler vials, sealed and used for fatty acid analysis. The fatty acid contents were analyzed using the procedure of Rule (1997) with suitable modifications. Particularly, gas chromatograph system (Varian star 3800, Varian, Inc., Walnut Creek, CA, USA) equipped with flame ionization detector was used to separate and identify the fatty acid components of the samples. The gas chromatography separation of components was carried out on a fused-silica bond capillary column $(30 \quad \mathrm{~m} \times 0.32 \quad \mathrm{~mm} \times 0.25 \mu \mathrm{m}$ film thickness, Omegawax 205) at split ratio of 100:1. Helium was used as the carrier gas. The oven temperature program used was as follows: $140^{\circ} \mathrm{C}$ for $5 \mathrm{~min}$, raised to $230^{\circ} \mathrm{C}$ at the rate of $10^{\circ} \mathrm{C}$ per min, and held at $230^{\circ} \mathrm{C}$ for $10 \mathrm{~min}$. The injector port and detector temperatures were $250^{\circ} \mathrm{C}$ and $260^{\circ} \mathrm{C}$ respectively. Individual fatty acids were confirmed on the basis of retention time through comparison with a commercially available mixture of fatty acids (PUFA No.2Animal Source, Supelco, Bellefonte, PA, USA). The fatty acid profile was expressed as percentages of individual fatty acids identified.

\section{Sensory evaluation}

Sensory characteristics of dry-cured loins at different days of ripening were evaluated by a trained twelve member panel. Briefly, the panelists with an average age of 30 to 35 years selected from the members of Animal Products Processing Division of the National Institute of Animal Science, Korea were used. Before the sensory evaluation, the panelists were trained using commercial cured meat products (e.g., dry-cured ham and loin) to familiarize them with the characteristics to be evaluated. Each dry-cured loin was tested by 12 panels allocated in randomized block arrangement. The dry-cured loin (each) was made into 12 thin slices $(0.5 \mathrm{~cm}$ thick) of about $10 \mathrm{~g}$ and immediately dispensed on individual plates. The panelists were laid to seat in private seats under fluorescent lighting and were served with the sensory samples in a random manner. The sensorial traits including color, flavor, taste, cured odor (intensity of the typical odor from cured meat products before the sample is eaten) and overall acceptability specifically selected for dry-cured loin evaluation (Martin et al., 2008) were used. The samples were evaluated by the panelists for the aforementioned sensorial traits using a 7-point scale (for the color, flavor, taste and acceptability where: 1 point = extremely undesirable and 7 point = extremely desirable; while for the cured odor where: $1=$ very low and 7 point $=$ vey high) as described by Meilgaard et al. (1991). The panelists were asked to refresh their mouth with the drinking distilled water and salt-free crackers between samples.

\section{Statistic analysis}

The data were subjected to statistical analysis using the Statistic Analysis System (SAS) package (SAS Institute, Cary, NC, USA, 2007). All data were analyzed by the 
general linear model procedure considering ripening period as the main effect. Means were compared using Duncan's multiple range test, with a significance of $p<0.05$.

\section{RESULTS AND DISCUSSION}

\section{Effect on ripening time on proximate composition}

Ripening time significantly $(\mathrm{p}<0.05)$ affected the proximate composition of dry-cured loins (Table 2). In particular, the protein and fat contents significantly increased at 60 days of ripening and did not increase thereafter, whereas the moisture content decreased as the ripening time increased $(\mathrm{p}<0.05)$. These findings agree with the general rule that moisture content is inversely related to ripening time in cured meat products (Andres et al., 2005). The increases in protein, ash and fat levels with increased ripening time could be attributed to the decreased moisture content which leads to an increase in dry-matter content in the dry-cured loins. Moisture content is one of the important technological traits that indicate the dryness as well as affect the shelf-life stability of dry-cured meat products. Our results indicated that the moisture content of dry-cured loins ripened for 60 days was similar to that $49 \%$ to $50 \%$ ) reported for the commercial dry-cured loins in literature (Alino et al., 2010). However, compared to the moisture content of commercial dry-cured loins as cited above, the 90 days-ripened loins had lower moisture content suggesting that the extending of ripening time may make the product become too dry, which probably affects the economic benefit. Similarly, the loins ripened for 60 days had similar protein content but lower ash and fat contents compared with those of the commercial dry-cured loins (Alino et al., 2010). These contrasting results could be due to difference in raw material source used between the products.

\section{Effect on technological quality traits}

The mean values of technological quality traits $(\mathrm{pH}$, water activity $\left(\mathrm{a}_{\mathrm{w}}\right)$, weight loss, TBARS and TVBN) are presented in Table 3. In general, the dry-cured loins at all ripening times examined were highly acidic, and the $\mathrm{pH}$ value significantly $(\mathrm{p}<0.05)$ increased from 30 to 90 days of

Table 2. Effect of ripening time on the proximate composition of dry-cured loin $(\mathrm{n}=34)$

\begin{tabular}{lcccc}
\hline \multirow{2}{*}{ Items } & \multicolumn{3}{c}{ Ripening time (d) } & \multirow{2}{*}{ SEM } \\
\cline { 2 - 4 } & 30 & 60 & 90 & \\
\hline Protein (\%) & $34.98^{\mathrm{c}}$ & $41.67^{\mathrm{ab}}$ & $43.88^{\mathrm{a}}$ & 0.64 \\
Ash (\%) & $1.60^{\mathrm{b}}$ & $1.68^{\mathrm{b}}$ & $2.84^{\mathrm{a}}$ & 0.12 \\
Moisture (\%) & $56.17^{\mathrm{a}}$ & $49.96^{\mathrm{b}}$ & $44.40^{\mathrm{c}}$ & 0.46 \\
Fat (\%) & $3.37^{\mathrm{b}}$ & $5.88^{\mathrm{a}}$ & $5.10^{\mathrm{a}}$ & 0.26 \\
\hline
\end{tabular}

SEM, standard error of means.

a-c Means with different letters in the same row differ significantly $(\mathrm{p}<0.05)$.
Table 3. Effect of ripening time on technological quality traits of dry-cured loin $(n=34)$

\begin{tabular}{lcccc}
\hline \multirow{2}{*}{ Items } & \multicolumn{3}{c}{ Ripening time (d) } & \multirow{2}{*}{ SEM } \\
\cline { 2 - 4 } & 30 & 60 & 90 & \\
\hline pH & $5.09^{\mathrm{b}}$ & $5.11^{\mathrm{ab}}$ & $5.15^{\mathrm{a}}$ & 0.01 \\
Water activity (a $)$ & $0.90^{\mathrm{c}}$ & $0.85^{\mathrm{ab}}$ & $0.83^{\mathrm{a}}$ & 0.01 \\
Weight loss (\%) & $35.05^{\mathrm{c}}$ & $47.23^{\mathrm{b}}$ & $50.92^{\mathrm{a}}$ & 1.18 \\
TBARS & $0.36^{\mathrm{c}}$ & $0.46^{\mathrm{b}}$ & $0.58^{\mathrm{a}}$ & 0.01 \\
$\quad(\mathrm{mg} \mathrm{MA} / \mathrm{kg} \mathrm{sample})$ & & & & \\
TVBN (mg \%) & $0.35^{\mathrm{b}}$ & $0.52^{\mathrm{a}}$ & $0.54^{\mathrm{a}}$ & 0.02 \\
\hline
\end{tabular}

SEM, standard error of means; TBARS, Thiobarbituric acid reactive substances; TVBN, total volatile basic nitrogen.

a-c Means with different letters in the same row differ significantly $(\mathrm{p}<0.05)$.

ripening. It is well known that the shelf-life stability of a food product is affected by several factors such as $\mathrm{pH}$ condition. In particular, the lower the $\mathrm{pH}$ the higher the acidity and therefore most of bacteria that contribute to food spoilage can't grow in acidic conditions.

Water activity $\left(\mathrm{a}_{\mathrm{w}}\right)$ decreased 0.05 units from 30 to 60 days $(\mathrm{p}<0.05)$ and did not continuously decrease as increasing ripening time up to 90 days. Soto et al. (2008) reported the $a_{w}$ value of 0.90 in dry-cured loins ripened at 100 days, was equal to the value of dry-cured loins ripened at 30 days but higher than that of loins ripened at 60 and 90 days in the present study. These contrasting results could be due to the difference in raw materials and processing conditions (e.g., temperature and humidity) between the studies. Weight loss significantly $(\mathrm{p}<0.05)$ increased with increased ripening time from $35.05 \%$ at 30 days to $47.23 \%$ and $50.92 \%$ at 60 and 90 days, respectively. This finding agrees with the general rule that weight loss is positively related to ripening time in cured meat products (Andres et al., 2005). However, the weight loss level of 60 daysripened loins in the present study were higher than that reported by Alino et al. (2010) for the loins ripened the same conditions, probably due to the differences in initial weights of raw loins used between the studies. According the industrial process where the loins are considered to have been fully processed when reaching around $40 \%$ weight loss (Alino et al., 2010), to achieve this recommended weight loss level, the loins in the present study took less than 60 days to get fully ripened. Therefore, the extended ripening time up to 90 days is unnecessary because it causes a high weight loss and high production cost which consequently leads to a low economic efficiency.

The lipid oxidation that occurs during ripening periods was determined using the TBARS test. The TBARS test is based on the measure of malonaldehyde which is a secondary product of lipid oxidation. It was observed that the levels of TBARS in dry-cured loins significantly $(p<0.05)$ increased with increased ripening time, indicating that the lipid oxidation in samples was more extensive as 
the ripening time increased. In general, our results agree with the general rule that lipid oxidation level in cured meat products is positively related to ripening time (Cava et al., 1999; Lorenzo et al., 2008). Hernandez et al. (1999) reported higher TBARS level (1.07 mg MA/kg) for pickledcured loins ripened for 30 days at $8^{\circ} \mathrm{C}$ and relative humidity of $72 \%$ to $82 \%$. Similarly, Ventanas et al. (2006) reported higher TBARS level in dry-cured loins ripened for 60 days at $10^{\circ} \mathrm{C}$ to $16^{\circ} \mathrm{C}$ and relative humidity of $75 \%$ to $85 \%$ compared with those observed in the present study.

Our results depicted that the TVBN significantly $(\mathrm{p}<0.05)$ increased from 30 to 60 days of ripening and did not increase thereafter. Compared to the TVBN levels of other cured meat products processed from ham material (Cilla et al., 2005; Cai et al., 2011; Seong et al., 2014), the dry-cured loins at all ripening periods examined had much lower amounts of TVBN, probably due to the differences in processing conditions (e.g., temperature, humidity, and ripening time) and the initial weight of raw materials used. The TVBN content contains mainly ammonia, trimethylamine and dimethylamine that are produced by either bacteria or enzymic degradation (Cai et al., 2011), and is considered as the important index of meat's freshness as well as shelf-life stability of products (Min et al., 2007).

\section{Effect on color}

Our results showed that the ripening time had only significant $(\mathrm{p}<0.05)$ effect on CIE L* (lightness) and CIE a* (redness) of dry-cured loins (Table 4). Particularly, the higher CIE L* and lower CIE a* values were found in 30 days-ripened samples compared with those of 90 daysripened samples, indicating that the lightness decreased and the redness increased as ripening time increased. The decrease in lightness could be explained due to the decrease in moisture content (Table 2) because the lightness is positively related to aqueous layer on the surface of muscle tissue (Hunt, 1980), while the redder color could be due to the increase in level of nitrosylmyoglobin which is formed by the reaction of nitric oxide (NO) on the myoglobin, and

Table 4. Effect of ripening time on the color characteristics of dry-cured loins $(\mathrm{n}=34)$

\begin{tabular}{|c|c|c|c|c|}
\hline \multirow{2}{*}{ Items } & \multicolumn{3}{|c|}{ Ripening time (d) } & \multirow{2}{*}{ SEM } \\
\hline & 30 & 60 & 90 & \\
\hline CIE L* & $48.88^{\mathrm{a}}$ & $47.78^{a}$ & $44.32^{\mathrm{b}}$ & 0.46 \\
\hline CIE a* & $7.04^{\mathrm{b}}$ & $7.43^{\mathrm{ab}}$ & $7.65^{\mathrm{a}}$ & 0.15 \\
\hline CIE b* & 3.11 & 2.81 & 2.84 & 0.20 \\
\hline $\mathrm{C}$ & 7.81 & 8.0 & 8.22 & 0.18 \\
\hline $\mathrm{h}^{\circ}$ & 30.46 & 21.15 & 27.33 & 0.78 \\
\hline
\end{tabular}

responsible for the typical bright red color of cured meat (Honikel, 2008). Compared with our data, those of Alino et al. (2010) found lower CIE a* values (5.7 to 6.3) in drycured loins processed with different formulations at 60 days of ripening. It was also observed that there were no differences ( $p>0.05)$ with respect to the colors between the 60 and 90 days ripened samples, with exception of lightness which was found higher in samples ripened for 60 days than that ripened for 90 days. In general, redness is considered as one of the most attractive color parameters of cured meat products (Honikel, 2008), however, the extended ripening time up to 90 days did not improve the redness, suggesting that the ripening beyond 60 days may not be effective in improving redness of dry-cured loins.

\section{Effect of ripening time on fatty acid profile}

The fatty acid composition in pork dry-cured loins has also been reported in previous studies (Hoz et al., 2007). However, how the changes occur in fatty acids during ripening periods have remained unknown. In this study, the changes in fatty acid composition of dry-cured loin during ripening periods were examined and we have found that the ripening time significantly affected most of fatty acids detected (Table 5). Regarding the monounsaturated fatty

Table 5. Effect of ripening time on the fatty acid composition (relative percentage) of dry-cured loin $(\mathrm{n}=34)$

\begin{tabular}{|c|c|c|c|c|}
\hline \multirow{2}{*}{ Items } & \multicolumn{3}{|c|}{ Ripening time (d) } & \multirow{2}{*}{ SEM } \\
\hline & 30 & 60 & 90 & \\
\hline C14:0 & $1.71^{\mathrm{a}}$ & $1.54^{\mathrm{ab}}$ & $1.34^{\mathrm{b}}$ & 0.05 \\
\hline $16: 0$ & 29.16 & 34.81 & 30.50 & 1.05 \\
\hline $\mathrm{C} 16: \ln 7$ & $3.59^{\mathrm{a}}$ & $2.82^{\mathrm{b}}$ & $2.44^{\mathrm{b}}$ & 0.1 \\
\hline C18:0 & 14.60 & 13.48 & 15.84 & 0.91 \\
\hline C18:1n9 & 38.36 & 38.56 & 40.22 & 1.66 \\
\hline $\mathrm{C} 18: \ln 7$ & $0.20^{\mathrm{a}}$ & $0.15^{\mathrm{b}}$ & $0.12^{\mathrm{b}}$ & 0.01 \\
\hline C18:2n6 & $9.57^{\mathrm{a}}$ & $6.84^{\mathrm{b}}$ & $7.55^{\mathrm{b}}$ & 0.17 \\
\hline C18:3n6 & $0.07^{\mathrm{a}}$ & $0.04^{\mathrm{b}}$ & $0.05^{\mathrm{b}}$ & 0.01 \\
\hline $\mathrm{C} 18: 3 \mathrm{n} 3$ & $0.36^{\mathrm{a}}$ & $0.30^{\mathrm{ab}}$ & $0.27^{\mathrm{b}}$ & 0.02 \\
\hline C20:1n9 & $0.89^{\mathrm{a}}$ & $0.73^{\mathrm{ab}}$ & $0.63^{\mathrm{b}}$ & 0.06 \\
\hline C20:4n6 & $1.30^{\mathrm{a}}$ & $0.68^{\mathrm{b}}$ & $0.85^{\mathrm{b}}$ & 0.08 \\
\hline $\mathrm{C} 22: 4 \mathrm{n} 6$ & $0.16^{\mathrm{a}}$ & $0.10^{\mathrm{b}}$ & $0.10^{\mathrm{b}}$ & 0.01 \\
\hline$\Sigma$ SFA & 45.47 & 49.83 & 47.68 & 1.91 \\
\hline$\Sigma U F A$ & 54.53 & 50.17 & 52.32 & 1.19 \\
\hline$\Sigma$ MUFA & 43.05 & 42.22 & 43.45 & 1.86 \\
\hline ¿PUFA & $11.48^{\mathrm{a}}$ & $8.87^{\mathrm{b}}$ & $7.95^{\mathrm{c}}$ & 0.56 \\
\hline MUFA/SFA & 0.95 & 0.91 & 0.94 & 0.06 \\
\hline PUFA/SFA & $0.25^{\mathrm{a}}$ & $01.9^{\mathrm{b}}$ & $0.17^{\mathrm{c}}$ & 0.01 \\
\hline
\end{tabular}

SEM, standard error of means; SFA, saturated fatty acid; UFA, unsaturated fatty acid; MUFA, monounsaturated fatty acid; PUFA, polyunsaturated fatty acid.

$\mathrm{SFA}=\Sigma(\mathrm{C} 14: 0+\mathrm{C} 16: 0+\mathrm{C} 18: 0)$.

MUFA $=\Sigma(\mathrm{C} 16: 1 \mathrm{n} 7+\mathrm{C} 18: 1 \mathrm{n}-7+\mathrm{C} 18: 1 \mathrm{n}-9+\mathrm{C} 20: 1 \mathrm{n}-9)$.

$\mathrm{PUFA}=\Sigma(\mathrm{C} 18: 2 \mathrm{n} 6+\mathrm{C} 18: 3 \mathrm{n} 3+\mathrm{C} 18: 3 \mathrm{n} 6+\mathrm{C} 20: 4 \mathrm{n} 6+\mathrm{C} 22: 4 \mathrm{n} 6)$

a-c Means with different letters in the same row differ significantly $(\mathrm{p}<0.05)$. 
acids (MUFA), there was a decrease in levels of some MUFA such as C16:1n7 (palmitoleic acid), C18:1n7 (cisvaccenic acid) and $C 20: \ln 9$ (eicosenoic acid) $(\mathrm{p}<0.05)$. Whereas, the level of oleic acid (C18:1n9) (the most predominant MUFA detected in all samples) showed an increasing trend as the ripening time increased but not significantly different between the ripening times examined ( $>0.05)$. More remarkably, the levels of all of polyunsaturated fatty acids (PUFAs) such as C18:2n6 (linoleic acid), C18:3n6 (gamma-linolenic acid), C18:3n3 ( $\alpha$-linolenic acid), C20:4n6 (arachidonic acid) and C22:4n6 (arachidonic acid) significantly $(\mathrm{p}<0.05)$ decreased as the ripening time increased. On the other hand, the levels of all of saturated fatty acids (SFA) remained unchanged during processing, with exception of C14:0 (myristic acid) which showed a decrease after 90 days of ripening. Similarly, the total SFA, unsaturated fatty acid (UFA), and contents remained stable during ripening, whereas the total PUFA content and PUFA/SFA ratio significantly $(\mathrm{p}<0.05)$ decreased as ripening time increased. These results indicate that the changes in PUFAs during ripening occurred more intensely compared with those in MUFAs and SFAs, presumably due to the increased oxidation of PUFAs with extended ripening time (Table 3 ).

Compared with our data, Hoz et al. (2007) reported higher levels of most UFAs for the Spanish dry-cured loins ripened for 25 days, probably due to the raw material and ripening time differences between the studies. Additionally, when compared to the levels of fatty acids in raw longissimus dorsi muscle of same breed (Kim et al., 2009), the dry-cured loins at all ripening times examined had generally lower levels of most PUFAs such as C18:2n6, C18:3n6 and C18:3n3. Unsaturated fats especially PUFAs, are well known as the healthy fats that have important functions in the body such as; cell growth and development, and prevention of diseases (Simopoulos, 1997). In the present study, however, the extension of ripening time up to 90 days caused a decrease in levels of UFAs; therefore solutions to prevent the loss of UFAs due to oxidation during processing process should be taken into account in order to assure the nutritional value of this product.

\section{Effect of ripening time on sensory characteristics}

Table 6 presents the results of sensory evaluation of drycured loins at different ripening times. In particular, significantly $(\mathrm{p}<0.05)$ higher color score was given by the panelists for the loins ripened for 60 days than that for the loins ripened for 30 days, but no differences between the 60 days and 90 days-ripened loins were observed for the color. Similarly, significantly $(\mathrm{p}<0.05)$ higher flavor score was found in the loins ripened for 90 days compared with that of loins ripened for 30 days, but no differences between the 60 days and 90 days-ripened loins were found. Regarding the
Table 6. Effect of ripening time on the sensory characteristics of dry-cured loins $(n=34)$

\begin{tabular}{lllll}
\hline \multirow{2}{*}{ Items } & \multicolumn{3}{c}{ Ripening time (d) } & \multirow{2}{*}{ SEM } \\
\cline { 2 - 4 } & \multicolumn{2}{c}{30} & \multicolumn{1}{c}{60} & 90 \\
\hline Color & $3.88^{\mathrm{b}}$ & $4.75^{\mathrm{a}}$ & $5.13^{\mathrm{a}}$ & 0.2 \\
Flavor & $4.23^{\mathrm{b}}$ & $4.60^{\mathrm{ab}}$ & $4.80^{\mathrm{a}}$ & 0.16 \\
Taste & 4.32 & 4.70 & 4.77 & 0.19 \\
Cured odor & $3.90^{\mathrm{a}}$ & $3.73^{\mathrm{ab}}$ & $3.40^{\mathrm{b}}$ & 0.14 \\
Overall acceptability & $4.12^{\mathrm{b}}$ & $4.62^{\mathrm{a}}$ & $4.78^{\mathrm{a}}$ & 0.17 \\
\hline
\end{tabular}

SEM, standard error of means.

a-b Means with different letters in the same row differ significantly $(\mathrm{p}<0.05)$.

taste, no difference in taste scores of samples between the ripening times were reported by the panelists $(p>0.05)$. Cured odor reflects the ripening degree of the cured meat products. In the present study, it was observed that the cured odor score of the products ripened for 30 days was significantly higher than that of loins ripened for 90 days, suggesting that curing odor is continuously declining during ripening. Additionally, the panelists gave higher overall acceptability scores for the dry-cured loins ripened for 60 and 90 days compared with those for loins ripened for 30 days. This might be due to association with the synergistic effect of their higher color and flavor scores.

The biochemical changes such as proteolysis and lipolysis that occur during ripening process are of great importance to the final sensory quality of dry-cured meat products (Hernandez et al., 1999). In which, the proteolysis and lipolysis produce a large number of volatile flavor compounds which subsequently contribute to typical flavor characteristics of the products (Ruiz et al., 2002). Therefore, the differences in flavor scores could be partially due to the differences in the biochemical changes between the ripening periods. On the other hand, it was suggested that rancid odor and flavor caused by the lipid oxidation could be the main factors resulting in a lower overall acceptability score of dry-cured loins (Hoz et al., 2007). However, the levels of TBARS in loins in our study were several times lower compared with those reported for other dry-cured loin types in literature (Hoz et al., 2007).

In conclusion, based on the results obtained in the present study, it can be concluded that the ripening time had a great impact on quality characteristics of dry-cured loin. Although, the ripening period of 30 days possessed lower $\mathrm{pH}$ value, TBARS, TVBN levels and weight loss, and higher UFAs levels compared with those of other remaining ripening periods (60 and 90 days) but had relatively high moisture content, which may results in a low shelf-life stability. Whereas, the extended ripening time up to 90 days resulted in increases in $\mathrm{pH}$ value, weight loss, TBARS and TVBN levels which may cause a reduction in final quality and economic benefit of the product. Considering all 
proximate composition, technological quality traits, lipid oxidation level and sensory characteristics examined in the present study, therefore, it is suggested that the ripening duration between 30 and 60 days could be more appropriate for producing dry-cured loin product with higher quality and economic benefits.

\section{ACKNOWLEDGMENTS}

This work was supported by "Cooperative Research Program for Agriculture Science \& Technology Development (Project No. PJ00984805)" Rural Development Administration, Republic of Korea.

\section{REFERENCES}

Alino, M., R. Grau, F. Toldra, E. Blesa, M. J. Pagan, and J. M. Barat. 2010. Physicochemical properties and microbiology of dry-cured loins obtained by partial sodium replacement with potassium, calcium and magnesium. Meat Sci. 85:580-588.

Andres, A. I., R. Cava, J. Ventanas, E. Muriel, and J. Ruiz. 2004. Lipid oxidative changes throughout the ripening of dry-cured Iberian hams with different salt contents and processing conditions. Food Chem. 84:375-381.

Andres, A. I., S. Ventanas, J. Ventanas, R. Cava, and J. Ruiz. 2005. Physicochemical changes throughout the ripening of dry cured hams with different salt content and processing conditions. Eur. Food Res. Technol. 221:30-35.

AOAC. 2000. Official Methods of Analysis of the AOAC 986.15 (pp. 1-8). Multi-element Method. (17th ed.). Arlington, VA, USA.

Cai, J., Q. Chen, X. Wan, and J. Zhao. 2011. Determination of total volatile basic nitrogen (TVB-N) content and WarnerBratzler shear force (WBSF) in pork using Fourier transform near infrared (FT-NIR) spectroscopy. Food Chem. 126:13541360.

Cava, R., J. Ruiz, J. Ventanas, and T. Antequera. 1999. Oxidative and lipolytic changes during ripening of Iberian hams as affected by feeding regime: extensive feeding and alphatocopheryl acetate supplementation. Meat Sci. 52:165-172.

Chiavaro, E., M. Rinaldi, E. Vittadini, and D. Barbanti. 2009. Cooking of pork Longissimus dorsi at different temperature and relative humidity values: Effects on selected physicochemical properties. J. Food Eng. 93:158-165.

Cilla, I., L. Martınez, J. A. Beltran, and P. Roncales. 2005. Factors affecting acceptability of dry-cured ham throughout extended maturation under "bodega" conditions. Meat Sci. 69:789-795.

FAO. 2013. Meat and Meat products. Food and Agriculture Organization. http://www.fao.org/ag/againfo/themes/en/meat/ home.html Accessed March 1, 2013

Flores, J. and F. Toldra. 1993. Curing: processes and applications. In: Encyclopaedia of Food Science, Food Technology and Nutrition (Eds. R. Macrae, R. Robinson, M. Saadle, and G. Fullerlove ). Academic Press, London, England. pp.1277-1282.

Folch, J., M. Lees, and G. H. Sloane-Stanley. 1957. A simple method for the isolation and purification of total lipides from animal tissue. J. Biol. Chem. 26:497-507.

Hernandez, P., J. L. Navarro, and F. Toldra. 1999. Lipolytic and oxidative changes in two Spanish pork loin products: drycured loin and pickled-cured loin. Meat Sci. 51:123-128.

Honikel, K. O. 2008. The use and control of nitrate and nitrite for the processing of meat products. Meat Sci.78:68-76.

Hoz, L., I. Cambero, C. Santos, B. Herranz, and J. A. Ordonez. 2007. Fatty acids and sensory characteristics of Spanish drycured loin enriched in acid $\alpha$-linolenic and $\alpha$-tocopherol. Food Chem. 101:1701-1706.

Hunt, M. C. 1980. Meat color measurements. Proceedings of $33^{\text {rd }}$ Annual Reciprocal Meat Conference, June 22-25th, 1980. Chicago, IL, USA.

Jonsall, A., L. Johanssona, K. Lundstrom, K. H. Andersson, A. N. Nilsen, and E. Risvika. 2002. Effects of genotype and rearing system on sensory characteristics and preference for pork $(M$. Longissimus dorsi). Food Qual. Prefer. 13:73-80.

Jurado, A., C. Garcia, M. L. Timon, and A. I. Carrapiso. 2007. Effect of ripening time and rearing system on amino acidrelated flavour compounds of Iberian ham. Meat Sci.75:585594.

Kim, D. H., P. N. Seong, S. H. Cho, J. H. Kim, J. M. Lee, C. Job, and D. G. Lim. 2009. Fatty acid composition and meat quality traits of organically reared Korean native black pigs. Livest. Sci. 120:96-102.

Lorenzo, J. M., M. C. Garcia-Fontan, I. Franco, and J. Carballo. 2008. Biochemical characteristics of dry-cured lacon (a Spanish traditional meat product) throughout the manufacture, and sensorial properties of the final product. Effect of some additives. Food Control 19:1148-1158.

Martin, D., T. Antequera, E. Muriel, T. Perez-Palacios, and J. Ruiz. 2008. Effect of dietary conjugated linoleic acid in combination with monounsaturated fatty acids on the meat composition and quality traits of dry-cured loin. Meat Sci. 80:1309-1319.

Meilgaard, M., G. Civille, and B. Carr. 1991. Sensory Evaluation Techniques (2nd ed.). CRC Press, Boca Raton, FL, USA.

Meinert, L., K. Tikk, M. Tikk, P. B. Brockhoff, W. L. P. Bredie, C. Bjergegaard, and M. D. Aaslyng. 2009. Flavour development in pork. Influence of flavour precursor concentrations in longissimus dorsi from pigs with different raw meat qualities. Meat Sci. 81:255-262.

Min, J. S., S. O. Lee, A. Jang, C. Jo, C. S. Park , and M. Lee. 2007. Relationship between the concentration of biogenic amines and volatile basic nitrogen in fresh beef, pork, and chicken meat. Asian Australas. J. Anim. Sci. 20:1278-1284.

Morrison, W. R. and L. M. Smith. 1964. Preparation of fatty acid methyl esters and dimethylacetals from lipids with boron fluoride-methanol. J. Lipid Res. 5:600-608.

Muriel, E., J. Ruiz, L. Martin, M. J. Petron, and T. Antequera. 2004. Physico-chemical and sensory characteristics of drycured loin from different Iberian pig lines. Food Sci. Technol. Int. 10:117-123.

Pikul, J., D. E. Leszczynski, and F. A. Kummerow. 1989. Evaluation of three modified TBA methods for measuring lipid oxidation in chicken meat. J. Agric. Food Chem. 37:1309-1313.

Ruiz, J., E. Muriel, and J. Ventanas. 2002. The flavor of Iberian ham. In: Research Advances in The Quality of Meat and Meat Products (Ed. F. Toldra). Research Signpost, Trivandrum, India. 
pp. 289-309.

Rule, D. C. 1997. Direct transesterification of total fatty acids of adipose tissue, and of freeze-dried muscle and liver with boron-trifluoride in methanol. Meat Sci. 46:23-32.

Seong, P. N., K. M. Park, S. M. Kang, G. H. Kang, S. H. Cho, B. Y. Park, and H. V. Ba. 2014. Effect of particular breed on the chemical composition, texture, color, and sensorial characteristics of dry-cured ham. Asian Australas. J. Anim. Sci. 27:1164-1173.

Simopoulos, A. P. 1997. $\omega-3$ fatty acids in the preventionmanagement of cardiovascular disease. Can J. Physiol. Pharmacol. 75:234-239.
Soto, E., L. Hoz, J. A. Ordonez, E. Hierro, B. Herranz, C. LopezBote, and M. I. Cambero. 2008. Impact of feeding and rearing systems of Iberian pigs on volatile profile and sensory characteristics of dry-cured loin. Meat Sci. 79:666-676.

Ventanas, S., M. Estevez, J. F. Tejeda, and J. Ruiz. 2006. Protein and lipid oxidation in Longissimus dorsi and dry cured loin from Iberian pigs as affected by crossbreeding and diet. Meat Sci.72:647-655.

Ventanas, S., J. Ventanas, and J. Ruiz. 2007. Sensory characteristics of Iberian dry-cured loins: Influence of crossbreeding and rearing system. Meat Sci. 75:211-219.

Vittadini, E., M. Rinaldi, E. Chiavaro, D. Barbanti, and R. Massini. 2005. The effect of different convection cooking methods on the instrumental quality and yield of pork Longissimus dorsi. Meat Sci. 69:749-756. 